\title{
Chromoblastomycosis: tissue modifications during itraconazole treatment ${ }^{\star}$
}

\author{
Kátia Sheylla Malta Purim ${ }^{1}$ \\ José Fillus Neto ${ }^{3}$
}

\author{
Murilo Calvo Peretti ${ }^{2}$ \\ Marcia Olandoski ${ }^{4}$
}

DOI: http:/ / dx.doi.org/10.1590/abd1806-4841.20175466

Abstract: BACKGROUND: Histological and mycological changes during itraconazole use have not been totally established in
chromoblastomycosis.
OBJECTIVEs: To evaluate tissue modifications in chromoblastomycosis carriers under itraconazole treatment.
METHODS: A histological retrospective study of 20 cases of chromoblastomycosis seen at the university hospital at the south of
Brazil, during itraconazole $400 \mathrm{mg}$ daily treatment. Patients were classified into two groups: plaque or tumor lesions, and un-
derwent periodic evaluations every four months during three years. Hematoxylin-eosin stain was used to analyze epidermal
modifications, inflammatory infiltrate and fibrosis, and Fontana-Masson stain for parasite evaluation.
RESULTS: Fontana-Masson stain was superior to hematoxylin-eosin stain in fungal count in the epidermis (mean difference=0.14;
p<0.05). The most distinct mycosis tissue responses were registered in the dermis. Epidermal thinning, granulomatous infil-
trate decrease or disappearance, fibrosis increase and quantitative/morphological changes occurred during treatment.
STUDY LIMITATIONS: Patients could not be located to have their current skin condition examined.
CONCLUSION: Parasitic and tissue changes verified in this study can reflect the parasite-host dynamics under itraconazole action. Keywords: Chromoblastomycosis; Histology; Itraconazole; Mycology; Pathology

\section{INTRODUCTION}

Chromoblastomycosis is a chronic disease caused by dematiaceus fungi found in soil and decaying vegetation, common in tropical and subtropical regions. ${ }^{1-3}$ Infection occurs by traumatic fungal inoculation into the skin, and mycosis is very prevalent in rural men. ${ }^{4-6}$ It is characterized by lesions of polymorphic, papillomatous, nodular, cauliflower, verruciform, hyperkeratotic, cicatricial, plaque or combinations, in the lower limbs, with no tendency to spontaneous cure (Figure 1). ${ }^{7}$

Chronic inflammatory infiltrate, microabscesses, darkbrown parasites and granulomatous process are frequent findings in histopathology. Suppurative granuloma rich in fungal cells is almost always observed in verrucous lesions, while tuberculoid granulomas with few parasites are mainly detected in cicatricial lesions and well-defined erythematous plaques, suggesting that verrucous lesions have a less competent tecidual inflammatory response. ${ }^{9}$ The muriform element is pathognomonic and observed in tissue biopsy specimens or by direct mycological examination from black dotted scrapings of the cutaneous lesion with $10 \% \mathrm{KOH}^{10}$
Little is known about histological alterations and variation of the positivity of mycological exams resulting from systemic treatments with antifungals. This study aims to analyze tissue changes during therapy with itraconazole.

\section{METHODS}

This is a histological study of cases of chromoblastomycosis from clinical research performed at a university hospital in the Southern region of Brazil. ${ }^{11,12}$ Patients were submitted to at least four biopsies of cutaneous lesions - one biopsy to diagnose the disease and a minimum of three biopsies to follow the tissue modifications during the treatment. Periodic evaluation occurred every four months, and participants were followed for three years from 1988 to 1991. The project to access this historical documentation was approved by the Ethics Committee (protocol 10835/2012).

Skin biopsies, always conducted by the same researcher, consisted of an ellipse of $1 \mathrm{~cm}$ of tissue on the largest axis, composed of epidermis, dermis and hypodermis, and were intended for mycological and histopathological study. In active lesions, biopsies were

\footnotetext{
Received on 04.12.2015.

Approved by the Advisory Board and accepted for publication on 28.05.2016.

* Study conducted at Hospital das Clínicas - Universidade Federal do Paraná (HC-UFPR) - Curitiba (PR), Brazil.

Financial support: None.

Conflict of interest: None.

Discipline of Dermatology of the Medical School - Universidade Positivo (UP) - Curitiba (PR), Brazil.

Dermatology Service of theHospital das Clínicas - Universidade Federal do Paraná (HC-UFPR) - Curitiba (PR), Brazil.

Dermatology Service of the Hospital Evangélico de Curitiba - Universidade Evangélica do Paraná - Curitiba (PR), Brazil.

Discipline of Biostatistics of the Medical School - Pontifícia Universidade Católica do Paraná (PUC-PR) - Curitiba (PR), Brazil. 
collected in regions of black dotted and/or erythematous borders. In healed lesions during treatment, biopsy was obtained from its border, and desquamative areas with granular appearance were selected. Hematoxylin-eosin (HE) staining was used to verify tissue changes, and HE and Fontana-Masson (FM) staining was used to evaluate fungi throughout the treatment (Chart 1). For the direct mycological examination, $10 \% \mathrm{KOH}$ solution was used and, for culture, Sabouraud agar medium.

Fungus count occurred on two slides, one stained by HE and the other stained by FM. Counting started always in the upper left corner of the slides, moving the chariot from top to bottom in the epidermis-hypodermic direction until the end of the histological section. Then the chariot was moved from left to right relative to the observer, moving a field at right angle and resuming the count from the bottom up in the hypodermis-epidermis direction. American Optical Spencer microscope was used, with a 40x objective lens and a 10x ocular lens. In the slides with more than one histological section, stained by HE, the section closest to the slide label, to the left of the observer, was

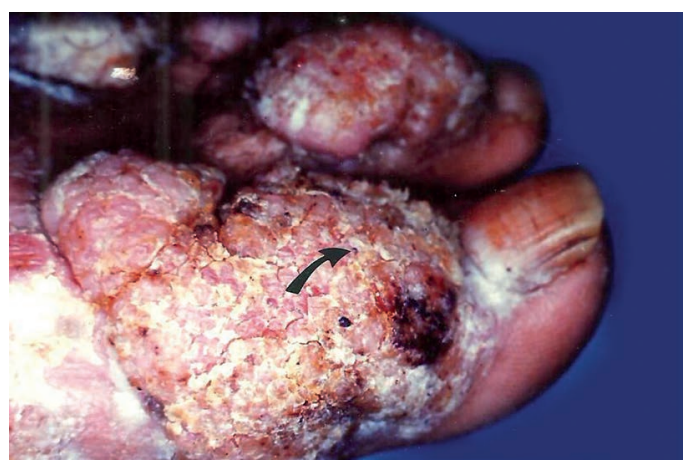

FIgURE 1: Clinical aspect of tumoral lesion with papillomatous surface, covered by black dots (arrow), on the dorsum of left foot used. A reticle was adapted to the 10WF CAT $176 \mathrm{AO}$ ocular lens to delineate areas of histological sections for counting.

In each slide, 100 reticulated areas were counted, registering only the spherical integral parasitic elements found in the odd-numbered reticulated areas. In order to avoid registering a parasite more than once, the following rule was adopted: the parasite that was located on the border lines of the reticulated area, left and above, was counted for this field. The parasite that was situated on the right and below did not belong to this field. For record purposes, each parasitic element found with or without septation, isolated or clustered, was equivalent to one unit. Artifact pigments, fragmented structures and hyphae were excluded from counting.

Criteria used to control the treatment were: clinical (complete healing of all lesions), mycological (absence of parasites at the direct mycological examination and culture) and histological (absence of parasites, absence of microabscesses, atrophy of the epidermis, replacement of the active granulomatous infiltrate in the dermis due to chronic inflammatory infiltrate and dense fibrosis).

In the statistical analysis, Kappa coefficients were estimated and 95\% confidence intervals were used to evaluate the concordance between mycological, histological and culture examinations. For the comparison of the HE and FM stainings, Student's t-test was used for paired samples. Comparison between tumor manifestation and plaque manifestation, in relation to the probability of having a clinical improvement or cure as final result, was performed using Fisher's exact test. For this same analysis, the relative risk was estimated. Values of $\mathrm{p}<0.05$ indicated statistical significance. Data were analyzed using IBM SPSS Statistics v.20 software.

\section{RESULTS}

The sample consisted of 20 individuals, white, adults, farmers, 17 of them were men, with mean age of 58.2 years and standard

CHART 1: Stainings used in cases of chromoblastomycosis and their purposes in the course of treatment with itraconazole

\begin{tabular}{|c|c|c|c|c|}
\hline \multicolumn{3}{|c|}{ STAINING } & \multicolumn{2}{|r|}{ PURPOSE } \\
\hline \multirow{10}{*}{$\begin{array}{l}\text { Hematoxy- } \\
\text { lin-eosin }\end{array}$} & \multicolumn{2}{|c|}{$\begin{array}{l}\text { Analysis of tissue } \\
\text { modifications }\end{array}$} & & Definition of the degree of tissue changes \\
\hline & Epidermis & Morphology & E1: & Atrophy: decreased epidermal thickness with loss of papillary pattern \\
\hline & & & E2: & Hyperplasia: increased number of epidermal cells \\
\hline & & & E3: & $\begin{array}{l}\text { Pseudoepitheliomatous hyperplasia: increased cell numbers, thickening of the } \\
\text { epidermis, rare mitoses without loss of polarity and elongation of the epithelial } \\
\text { cones with epidermal shoots within the dermis }\end{array}$ \\
\hline & Dermis & Inflammatory & D1: & Local lymphoplasmo-histiocytic \\
\hline & & infiltrate & D2: & Lymphoplasmo-histiocytic and mononuclear with sparse granulomas \\
\hline & & & D3: & $\begin{array}{l}\text { Lymphoplasmo-histiocytic, polymorphonuclear and mononuclear with various } \\
\text { granulomas and microabscesses }\end{array}$ \\
\hline & Hipodermis & Tissue fibrosis & F1: & Predominantly in hypodermis \\
\hline & & & F2: & Predominantly in hypodermis and reticular dermis \\
\hline & & & F3: & In hypodermis, reticular and papillary dermis \\
\hline Fontana- & & & & Parasite analysis in host tissue \\
\hline Masson & & stribution of $\mathrm{fu}$ & in th & epidermis, dermis and hypodermis and visualization of their aspects \\
\hline
\end{tabular}


deviation of 11.1 years (42 to 82 years) and 3 women aged 33 to 54 years (mean age of 41.6 and standard deviation of 11.0 years), all receiving treatment with itraconazole $200-400 \mathrm{mg} /$ day. During the study, 135 skin biopsies were performed with a mean of 6.7 biopsies/patient.

Prior to treatment, direct mycological examination was positive in $80 \%$ of cases; culture in $85 \%$; and histological examination, in $100 \%$ (Figure 2). Culture and microculture allowed the identification of F. pedrosoi in $100 \%$ of the patients (Figure 3). During follow-up, there was a good level of concordance between mycological (direct and culture) and histopathological examination (Kappa: 0.64; 95\% CI: 0.51 to 0.76 ); between culture and direct mycological examination (Kappa: 0.67, 95\% CI 0.55 to 0.80 ); and between culture and histopathological examination (Kappa: $0.71,95 \%$ CI: 0.59 to 0.84 ).

Tissue modifications of the skin during treatment with itraconazole were significant in the epidermis, dermis and hypodermis when the results of the baseline evaluation (month 0 ) were compared with the results observed in the period from 9 to 12 months after treatment. In the comparison between the baseline and the 4 to 8 months period, the results indicated significant differences for the epidermis and dermis, with a tendency towards significance for fibrosis. Between the period of 4 to 8 months and the period of 9 to 12 months, a significant difference was found for the intensity of fibrosis (Table 1).

Figure 4 illustrates histological aspect prior to treatment. Figure 5 shows parasitic elements in the middle of the dermal inflammatory infiltrate.

Comparing the visualization of the fungi in the FM and HE stainings, it was verified that their identification was facilitated by the FM staining, mainly in the epidermis (mean difference of 0.14 fungus and standard deviation of 0.50, $\mathrm{p}<0.05$ ) (Figure 6).

In the final evaluation, of the 11 patients with tumor manifestation, $9(82 \%)$ presented improvement or clinical cure and 2 (18\%) presented clinical and biological cure. Of the 9 patients with plaque manifestations, $3(33 \%)$ presented improvement or clinical cure and the other $6(67 \%)$ presented clinical and biological cure $(\mathrm{p}=$ 0.065). Therefore, it is estimated that, for cases with tumor manifestation, the relative risk of having clinical improvement or cure (and not clinical and biological cure) is 2.5 times, when compared with cases with plaque manifestation.

\section{DISCUSSION}

In this study, before the institution of the treatment, the direct mycological examination was positive in $80 \%$ of the cases; culture in $85 \%$; and histological examination in $100 \%$. As the mycosis presents centrifugal growth, choosing areas of black dotted region and active lesions borders or, in the absence of these borders, of cicatrized lesions guided the investigation of fungi, which allowed equivalence between the positivity of the mycological and histological exams. Culture and microculture allowed the identification of $F$. pedrosoi as an etiological agent of all cases, according to the literature. ${ }^{8,13-16}$

In chromoblastomycosis, the tissue response to the fungus is non-specific and may be similar to other deep mycoses. Most epidermal tissue alterations on histopathological examination are hyperkeratosis and pseudoepitheliomatous hyperplasia. In der- mal and hypodermal tissues, non-specific diffuse inflammatory infiltrates are detected. ${ }^{17}$ Other findings include suppurative and granulomatous reactions, sclerotic bodies and acanthosis with transepidermal fungal elimination. ${ }^{3,18-22}$ In this study, the intensity and type of histological response were modified according to patient and therapeutic phase. Before treatment, there was a tendency to an exuberant inflammatory condition, epidermis with hyperkeratosis, parakeratosis, leukocyte crusts, Malpighian layer acanthosis, spongiosis, neutrophil and eosinophil exocytosis and microabscesses. Acanthosis was irregular, with typical cells and hypertrophy of the papillae protruding above the cutaneous surface, with enlargement and bifurcation of the interpapillary ridges, constituting pseudoepitheliomatous hyperplasia.

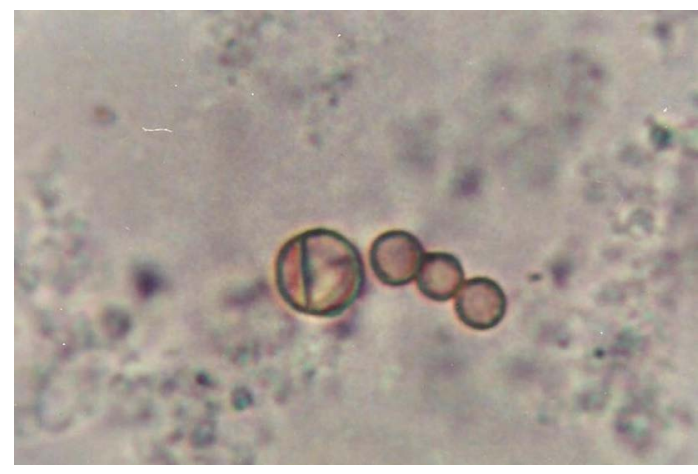

Figure 2: Positive direct mycological examination: brown spherical parasite elements, with and without septation, observed on tissue fragment with $\mathrm{KOH}$ (x1000)
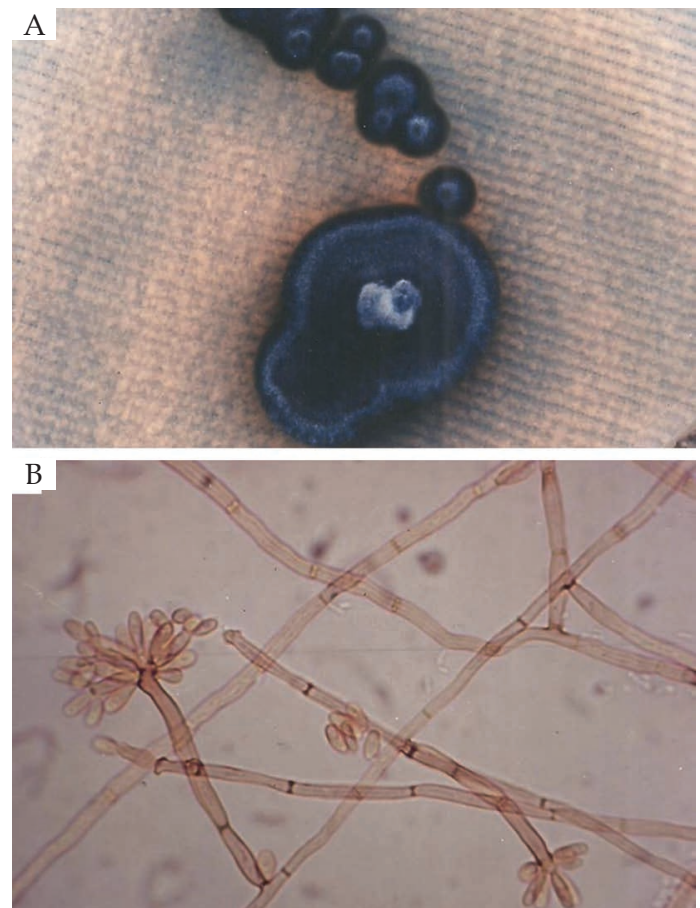

Figure 3: A) Colony morphology of Fonsecaea pedrosoi in Sabouraud-dextrose-agar medium after 21 days of incubation; B) Microculture of Fonsecaea pedrosoi (X1000) 


\begin{tabular}{|c|c|c|c|c|c|c|}
\hline \multirow{2}{*}{$\begin{array}{l}\text { Evaluation phase } \\
\text { (month) }\end{array}$} & \multicolumn{2}{|c|}{ Epidermis morphology } & \multicolumn{2}{|c|}{ Dermal inflammatory infiltrate } & \multicolumn{2}{|c|}{ Fibrosis intensity } \\
\hline & $\mathrm{E} 1+\mathrm{E} 2$ & E3 & $\mathrm{D} 1+\mathrm{D} 2$ & D3 & F1 & $\mathrm{F} 2+\mathrm{F} 3$ \\
\hline 0 & $5(25 \%)$ & $15(75 \%)$ & $5(25 \%)$ & $15(75 \%)$ & $20(100 \%)$ & $0(0 \%)$ \\
\hline 4 to 8 & $14(70 \%)$ & $6(30 \%)$ & $14(70 \%)$ & $6(30 \%)$ & $15(75 \%)$ & $5(25 \%)$ \\
\hline 9 to 12 & $18(90 \%)$ & $2(10 \%)$ & $17(85 \%)$ & $3(15 \%)$ & $8(40 \%)$ & $12(60 \%)$ \\
\hline Compared phases & \multicolumn{2}{|c|}{ P value } & \multicolumn{2}{|c|}{ P value } & \multicolumn{2}{|c|}{ P value } \\
\hline $0 \times 4$ to 8 & \multicolumn{2}{|c|}{0.004} & \multicolumn{2}{|c|}{0.004} & \multicolumn{2}{|c|}{0.062} \\
\hline $0 \times 9$ to 12 & \multicolumn{2}{|c|}{$<0.001$} & \multicolumn{2}{|c|}{$<0.001$} & \multicolumn{2}{|c|}{$<0.001$} \\
\hline 4 to $8 \times 9$ to 12 & \multicolumn{2}{|c|}{0.125} & \multicolumn{2}{|c|}{0.250} & \multicolumn{2}{|c|}{0.016} \\
\hline
\end{tabular}

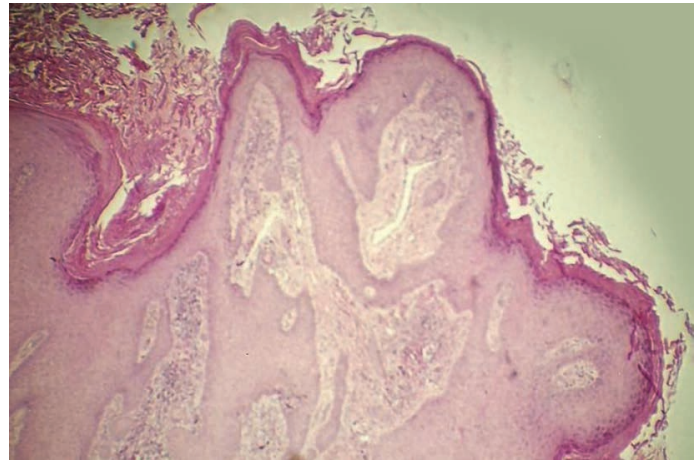

FIGURE 4: Pretreatment histological aspect: hyperkeratosis, pseudoepitheliomatous hyperplasia and dermal inflammatory infiltrate (Hematoxylin \& eosin, X40)
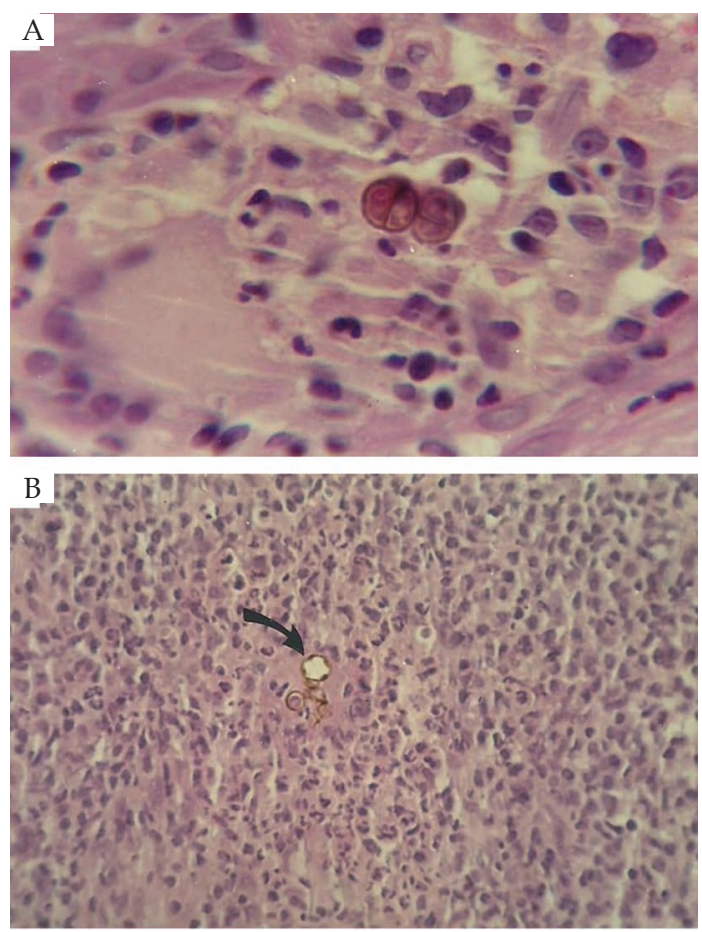

FIGURE 5: A) Septated parasitic elements in the middle of the suppurative and granulomatous inflammatory infiltrate (Hematoxylin \& eosin, X1000); B) Parasitic elements with signs of degeneration (arrow) in the middle of the inflammatory infiltrate (Hematoxylin \& eosin, X40)
The most distinct alterations in this study were found in the dermis. Before treatment, hyperplasia, papillomatosis, vascular neoformation and dilations, and edema were noted. The cellular infiltrate combined suppurative and granulomatous foci, being the parasites found amidst the inflammatory response or inside giant cells. The stratum corneum microabscesses probably corresponded to the black dots, observed macroscopically in the skin surface, resulting from transepithelial elimination and from the presence of dermoepidermal fistulas draining outwards. Throughout the treatment, there was progressive atrophy of the epidermis, decrease or disappearance of the granulomatous infiltrate and increase in the degree of fibrosis. Findings such as disappearance of microabscesses and granulomas, disappearance of parasites to mycological exams (direct and culture) and clinical healing of all the lesions allowed the support of the cure criteria, being able to be used to interrupt the treatment and follow up of the cases. ${ }^{23}$
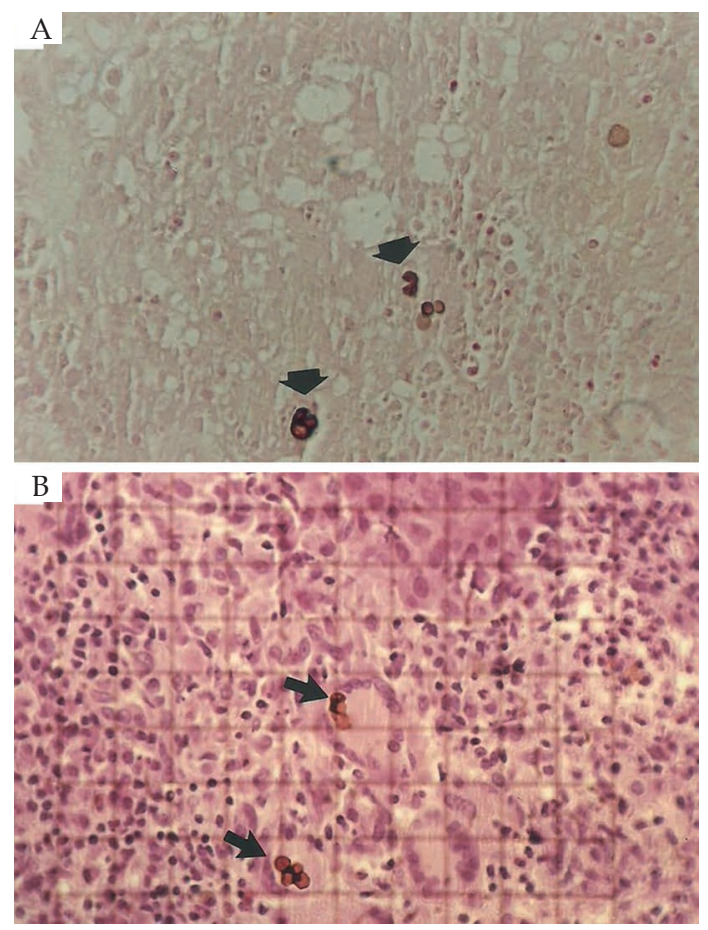

Figure 6: A) Septated parasitic elements (arrows) in the dermis (Fontana-Masson coloration, X40); B) Parasitic elements (arrows) in the dermis, delimited by reticulated area for counting (Hematoxylin \& eosin, X40) 
FM staining was superior to HE staining in detecting fungi with a lighter shade, mainly in the epidermis. Due to their natural pigmentation, these parasites are easily identified on uncolored slides. Special stainings like FM are useful for demonstrating hyphae in keratinized layers. ${ }^{24}$ In general, fungi detected in the histological sections had the following aspects: demaceous hyphae and septated spherical parasitic elements in one plane, in two planes (muriform element) or without septation, representing the metamorphism of the parasite, not being necessary the exclusiveness of the muriform element for the diagnosis of the disease.

In this study, the finding of hyphae in the epidermis was occasional. Parasites presented predominantly dermal location, followed by epidermal, which could be explained by changes in the thickness of their cell wall and decrease of the melanin pigmentation. The location on the surface allows transformation to mycelial form. Fungi located in the dermis undergo the phenomenon of parasitic reduction and generally have a thicker and pigmented wall due to adverse conditions to their parasitism: tissue pressure, local acidification and suppurative and granulomatous inflammatory reaction. Although curious, data on parasite count would lack better investigation, since the amount of fungi recorded was neither static nor definitive, since the histological section represented only one plane of a process that is essentially evolutionary and three-dimensional.

There was a greater tendency for clinical improvement or cure in tumoral forms when compared with plaque manifestation. Favorable clinical evolution during treatment was correlated to negative mycological exams, slower growth of cultures, or non-development of the fungus, and a predominance of histopathology with isolated parasites, reduced in size, with a clearer cell wall, without septation and cytoplasmic organelles, with signs of degeneration. Patients with a less favorable clinical response were positive for mycological exams and presented predominance of parasites with a thickened, well pigmented cell wall with a tendency to cluster, septation and intracytoplasmic organelles, possibly resulting from an adaptive mechanism of sclerotic bodies to escape from the body's defense. ${ }^{25-28}$ The amount of parasites recorded did not appear to interfere with clinical manifestation prior to treatment. However, the excessive number of parasites and the higher frequency of transepithelial elimination in the most exuberant cases suggest that host factors can determine the quality and quantity of the tissue response.

Limitations of this research were the absence of electron microscopy for a better evaluation of parasitic modifications and immunological techniques for investigation of circulating antigens that could complement the findings of the biopsies with other more specific and sensitive methods. In addition, it was not possible to locate the patients and verify their current skin condition, since most of them came from rural environments in other municipalities and lost hospital follow-up.

\section{CONCLUSION}

In this study, there was a greater tendency for clinical improvement or cure of tumoral forms when compared with plaque manifestation. There was concordance between the positivity of mycological and histological exams during treatment. The FM staining facilitated the demonstration of fungi in the epidermis. The most distinct tissue responses of mycosis were recorded in the dermis, with tissue and parasitic changes occurring during treatment with itraconazole, which may reflect parasite-host dynamics.

\section{ACKNOWLEDGEMENTS}

To Dr. Flávio de Queiroz Telles Filho for his encouragement during the mycological study. 


\section{REFERENCES}

1. Garnica M, Nucci M, Queiroz-Telles F. Difficult mycoses of the skin: advances in the epidemiology and management of eumycetoma, phaeohyphomycosis and chromoblastomycosis. Curr Opin Infect Dis. 2009;22:559-63.

2. Queiroz-Telles F, Nucci M, Colombo AL, Tobón A, Restrepo A. Mycoses of implantation in Latin America: an overview of epidemiology, clinical manifestations, diagnosis and treatment. Med Mycol. 2011;49:225-36.

3. Correia RTM, Valente NYS, Criado PR, Martins JEC. Cromoblastomicose: relato de 27 casos e revisão da literatura. An Bras Dermatol. 2010;85:448-54.

4. López Martínez R, Méndez Tovar LJ. Chromoblastomycosis. Clin Dermatol. 2007;25:188-94.

5. Santos AL, Palmeira VF, Rozental S, Kneipp LF, Nimrichter L, Alviano DS, et al. Biology and pathogenesis of Fonsecaea pedrosoi, the major etiologic agent of chromoblastomycosis. FEMS Microbiol Rev. 2007;31:570-91.

6. Suh MK, Lee YH. Infectious caused by dematiaceous fungi. Korean J Med Mycol. 2005; 10:77-82.

7. Alva ZB. Cromomicosis: Clínica y tratamiento; situación epidemiológica en Latinoamérica. Rev Perú Med Exp Salud Pública. 2004;21:167-75.

8. Mouchalouat Mde F, Gutierrez Galhardo MC, Zancopé-Oliveira RM, Monteiro Fialho PC, de Oliveira Coelho JM, Silva Tavares PM, et al. Chromoblastomycosis: a clinical and molecular study of 18 cases in Rio de Janeiro, Brazil. Int J Dermatol. 2011:50:981-6.

9. Avelar-Pires C, Simoes-Quaresma JA, Moraes-de Macedo GM, Brasil-Xavier M, Cardoso-de Brito A.. Revisiting the Clinical and Histopathological Aspects of Patients with Chromoblastomycosis from the Brazilian Amazon Region. Arch Med Res. 2013:44:302-6.

10. Pang KR, Wu JJ, Huang DB, Tyring SK. Subcutaneous fungal infections. Dermatol Ther. 2004:17:523-31.

11. Queiroz-Telles F, Purim KS, Fillus JN, Bordignon GF, Lameira RP, Van Cutsem J, et al. Itraconazole in the treatment of chromoblastomycosis due to Fonsecaea pedrosoi. Int J Dermatol. 1992;31:805-12.

12. Purim KSM. Cromoblastomicose: aspectos histológicos e micológicos durante 0 tratamento com itraconazol [dissertação]. Curitiba (PR): Universidade Federal do Paraná; 1991. $60 \mathrm{p}$.

13. Khan S, Kumar A, Vinod V, Prabhakar V, Eapen M, Thomas J, et al. Chromoblastomycosis due to Fonsecaea pedrosoi: an old wine in a rare bottle. $J$ Infect Dev Ctries. 2015;9:325-9.

14. Silva JP, de Souza W, Rozental S. Chromoblastomycosis: a retrospective study of 325 cases on Amazonic Region (Brazil). Mycopathologia. 1998-1999;143:171-5.

15. Minotto R, Bernardi CD, Mallmann LF, Edelweiss MI, Scroferneker ML. Chromoblastomycosis: a review of 100 cases in the state of Rio Grande do Sul, Brazil. J Am Acad Dermatol. 2001;44:585-92.

16. Kim DM, Hwang SM, Suh MK, Ha GY, Choi GS, Shin J, et al. Chromoblastomycosis caused by Fonsecaea pedrosoi. Ann Dermatol. 2011;23:369-74.

17. Krzyściak PM, Pindycka-Piaszczyńska M, Piaszczyński M. Chromoblastomycosis. Postepy Dermatol Alergol. 2014;31:310-21.

18. Pradhan SV, Talwar OP, Ghosh A, Swami RM, Shiva Raj KC, Gupta S. Chromoblastomycosis in Nepal: A study of 13 cases. Indian J Dermatol Venereol Leprol. 2007;73:176-8.

19. Uribe F, Zuluaga Al, Leon W, Restrepo A. Histopathology of chromoblastomycosis. Mycopathologia. 1989;105:1-6.

20. Yap FB. Chromoblastomycosis in Sarawak, East malaysian Borneo. Trans R Soc Trop Med Hyg. 2010;104:168-9.

21. Marques GF, Masuda PY, Sousa JM, Barreto JA, Wachholz PA. Clinical and demographic profile of chromoblastomycosis in a referral service in the midwest of São Paulo state (Brazil). An Bras Dermatol. 2015;90:140-2.

22. Criado PR, Valente NYS, Brandt HRC, Belda Jr W, Halpern I. Dermatite verrucosa de Pedroso e Gomes (Cromomicose): 90 anos depois, ainda entre nós. An Bras Dermatol. 2010;85:104-5.

23. Ameen M. Managing chromoblastomycosis. Trop Doct. 2010;40:65-7.

24. Chavan SS, Kulkarni MH, Makannavar JH. 'Unstained' and 'de stained' sections in the diagnosis of chromoblastomycosis: A clinico-pathological study. Indian J Pathol Microbiol. 2010;53:666-71.
25. da Silva JP, Alviano DS, Alviano CS, de Souza W, Travassos LR, Diniz JA, et al. Comparison of Fonsecaea pedrosoi sclerotic cells obtained in vivo and in vitro: ultrastructure and antigenicity. FEMS Immunol Med Microbiol. 2002;33:63-9,

26. da Silva JP, da Silva MB, Campelo SR, Salgado UI, Diniz JA, Esterre P, et al. TGF-beta plasma levels in chromoblastomycosis patients during itraconazole treatment. Cytokine. 2010;51:202-6.

27. Lee MW, Hsu S, Rosen T. Spores and mycelia in cutaneous chromomycosis. J Am Acad Dermatol. 1998;39:850-2.

28. Queiroz-Telles F. Chromoblastomycosis: a neglected tropical disease. Rev Inst Med Trop Sao Paulo. 2015;57:46-50.

\author{
MAILING ADDRESS: \\ Kátia Sheylla Malta Purim \\ Serviço de Dermatologia \\ R. General Carneiro, 181- Centro \\ 80060-900 - Curitiba, PR \\ Brazil \\ Email:kspurim@gmail.com
}

How to cite this article: Purim KSM, Peretti MC, Fillus Neto J, Olandoski M. Chromoblastomycosis: tissue modifications during itraconazole treatment. An Bras Dermatol. 2017;92(4):478-83. 